\title{
PLASMA-POWDER SURFACING OF NICKEL AND COBALT ALLOYS ON COPPER AND ITS ALLOYS
}

\author{
E.F. PEREPLYOTCHIKOV \\ E.O. Paton Electric Welding Institute, NASU \\ 11 Bozhenko Str., 03680, Kiev, Ukraine. E-mail: office@paton.kiev.ua
}

\begin{abstract}
The article deals with results of investigation of properties of nickel and cobalt alloys, deposited on copper or its alloys. Investigations of corrosion resistance of these alloys at different types of corrosion (solid, contact, crevice, cavitation-erosion fracture), as well as their antifriction properties and adhesion strength showed that the most acceptable as to the combination of properties are alloys NKh16SR2 and KKh30N6VSR. The technology of automatic plasma-powder surfacing of these alloys on aluminum bronze Br.AZhNMts94-4-1 was developed providing a quality joining of the deposited metal and the base one. The technology and equipment found application in surfacing of parts of ship pipeline fittings. 4 Ref., 1 Table, 6 Figures.
\end{abstract}

$\boldsymbol{K} \boldsymbol{e} \boldsymbol{y} \boldsymbol{w} \boldsymbol{O} \boldsymbol{r} \boldsymbol{d} \boldsymbol{s}:$ plasma-powder surfacing, surfacing on copper, surfacing technology, cobalt- and nickel-based alloys, corrosion, antifriction properties

Surfacing of Ni- and Co-based alloys on copper and its alloys is a rather complicated technical problem since the materials being joined differ greatly by their thermal, mechanical and operational properties. Thus, melting temperature of the mentioned alloys is by $300-350{ }^{\circ} \mathrm{C}$ higher than that of copper and its alloys. The possibility of conducting surfacing itself at the penetration depth of base metal being acceptable for practical purposes becomes problematic. In addition, during solidification process of weld pool metal between an already solidified deposited metal and solid base metal a layer of liquid copper (copper alloy) can remain, which may lead to delamination of the deposited and base metals.

The serious problems in surfacing arise also due to high thermal conductivity of copper and its alloys, i.e. at the beginning of surfacing when a workpiece is cold there is a high risk of lack of fusions; at the end of surfacing (especially when sizes of workpiece are small) the penetration depth of base metal inadmissibly increases. To eliminate these defects it is necessary to change the mode parameters in the surfacing process. The effective thermal capacity of the arc must be adjusted independently of the filler material feed rate.

Iron and cobalt have a limited solubility in copper, and the latter, in its turn, has a limited solubility in iron and cobalt. Therefore, in surfacing of cobalt and iron alloys on copper and copper alloys the problems of metallurgical character occur.

(C) E.F. PEREPLYOTCHIKOV, 2015
As the preliminary investigations showed, these problems can be solved by using plasmapowder surfacing, which is characterized by [1]:

- negligible penetration of base metal;

- lower temperature of weld pool metal and shorter time of contacting molten metal with a solid one at the fusion boundary as compared to the arc surfacing;

- possibility of separate control of heating the base metal and the filler powder feeding that allows taking into account the change in conditions of heat removal from the weld pool at different stages of surfacing process;

- ability to conduct surfacing at direct and reversed polarity at full automation of the process;

- saving consumption of surfacing consumables;

- small allowances for machining of the deposited parts.

Materials and methods of investigations. For investigations as the surfacing materials the powders of alloys based on nickel PR-NKh16SR2 and PR-NKh25S5R, and based on cobalt PRKKh30N6VSR were chosen. Plasma-powder surfacing of specimens was performed on the serial surfacing equipment completed with a plasmatron with distributed side supply of powder into the arc, that provides the widest opportunities for control of filler material heating [1]. All the mentioned powders were produced by spraying the molten metal with nitrogen under the industrial conditions. The fraction of powders was $63-100 \mu \mathrm{m}$. As the base metal, aluminum bronze Br.AZhNMts94-4-1 was selected. The surfacing was carried out in a single layer without preheating; after surfacing the specimens were cooled in air.

According to the conditions of service of parts of pipeline fittings operating in contact with sea 
water, the deposited metal of parts of chemical plants and other equipment must have the high antifriction properties as well as wear and corrosion resistance.

The corrosion resistance of alloys at different types of corrosion (solid, contact, crevice, cavitation-erosion fracture), and also their antifriction properties and adhesion strength with the base metal were investigated.

The tests for continuous and contact corrosion as well as cavitation-erosion fracture were carried out in synthetic sea water at $20{ }^{\circ} \mathrm{C}$ for $2000 \mathrm{~h}$. During testing of the alloys investigated for contact corrosion the ratio of areas of deposited metal and bronze was equal to $1: 1$. In the process of testing the potentials of contacting couple, i.e. deposited metal and bronze, were measured.

The tests for crevice corrosion were carried out in synthetic sea water at $75-80{ }^{\circ} \mathrm{C}$ during $2000 \mathrm{~h}$. The specimens were mounted in the special cells having slots to create a clearance gap between the surface of specimen and material of the cell.

The tests for cavitation-erosion fracture were carried out on the spindle device at $12 \mathrm{~m} / \mathrm{s}$ speed of rotation of specimens. After finishing of corrosion tests the specimens were etched in solution of oxalic-acid aluminum with the purpose of complete removal of corrosion products, washed out, dried and weighed, then the corrosion rate of each material was determined.

Investigation of antifriction properties was performed on the stand simulating the conditions of operation of parts of gate shutter valves. The speed of reciprocating movement was $0.02 \mathrm{~m} / \mathrm{s}$, the number of operating cycles was 2000 at the travel of specimens to one direction for $10 \mathrm{~mm}$. The specific pressure was $400 \mathrm{MPa}$, the lubricant was water. The inspection of specimens was carried out every $5,10,20,50,100,500$ and then every 500 cycles of double travels with registration of operating surfaces condition. The operability of couple and coefficient of friction were determined.

The adhesion strength of deposited metal with bronze was evaluated at rupture tensile testing (Figure 1). The loading rate was $6 \mathrm{~mm} / \mathrm{min}$.

Results of investigations. The rate of continuous corrosion of the tested nickel and cobalt alloys in the environment of sea water does not exceed $0.003 \mathrm{~g} /\left(\mathrm{m}^{2} \cdot \mathrm{h}\right)$, which according to the ten-point scale of corrosion resistance refers to point 1 of GOST 13819-68, and the metal itself is classified as a «highly resistant». In the tests for contact corrosion in all the three cases, the potential of deposited metal is moved to a nega-

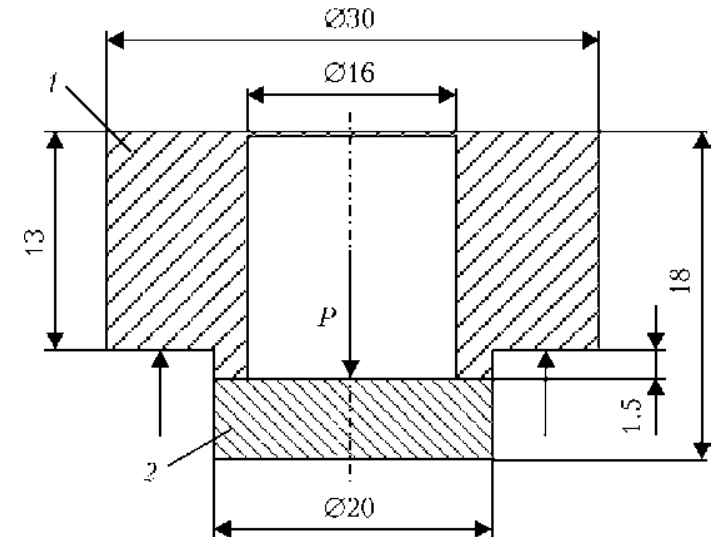

Figure 1. Specimen for rupture tensile test of deposited layer: 1 - base metal; 2 - deposited metal

tive side from the steady value and amounts to $0.15 \mathrm{~V}$. In the slotted gaps the surface of investigated alloys is characterized by negligible corrosion roughness. The bronze in the fusion zone under these conditions was subjected to a selective corrosion. Cavitation-erosion fracture in all the alloys is absent.

During investigation of antifriction properties of the deposited metal on tested specimens with deposits of type NKh25S5R the burrs were revealed after 100 cycles of double travels (see the Table).

As is seen from the Table, the best antifriction properties belong to alloys NKh16SR2 and KKh30N6VSR. In particular, the ability of alloy NKh16SR2 to polish itself during the test determines the lowest coefficient of friction in shear from the place (initiation) and in the movement. Alloys NKh16SR2 and KKh30N6VSR fully meet the requirements specified to stop valves of pipe fittings.

The mechanical and operational properties of bimetal products are largely determined by the properties of fusion boundary. As is seen from the Table, the metal in the fusion zone of cobalt and nickel alloys is characterized by satisfactory

Antifriction properties of deposited metal and its adhesion strength to bronze

\begin{tabular}{||l|c|c|c||}
\hline Grade of powder & $\begin{array}{c}\text { Change in } \\
\text { coefficients of } \\
\text { initiation/ } \\
\text { movement }\end{array}$ & $\begin{array}{c}\text { Number of } \\
\text { cycles before } \\
\text { burr }\end{array}$ & $\begin{array}{c}\text { Adhesion } \\
\text { strength, } \\
\text { MPa }\end{array}$ \\
\hline PR-NKh16SR2 & $\frac{0.218-0.253}{0.168-0.177}$ & 2000 & $\frac{205-367}{294}$ \\
\hline PR-NKh25S5R & $\frac{0.168-0.486}{0.134-0.454}$ & 100 & $\frac{202-298}{261}$ \\
\hline PR-KKh30N6VSR & $\frac{0.219-0.436}{0.185-0.404}$ & 2000 & $\frac{253-410}{334}$ \\
\hline
\end{tabular}

' In numerator the limit values and in denumerator the average values are given according to the test results of 4 specimens. 


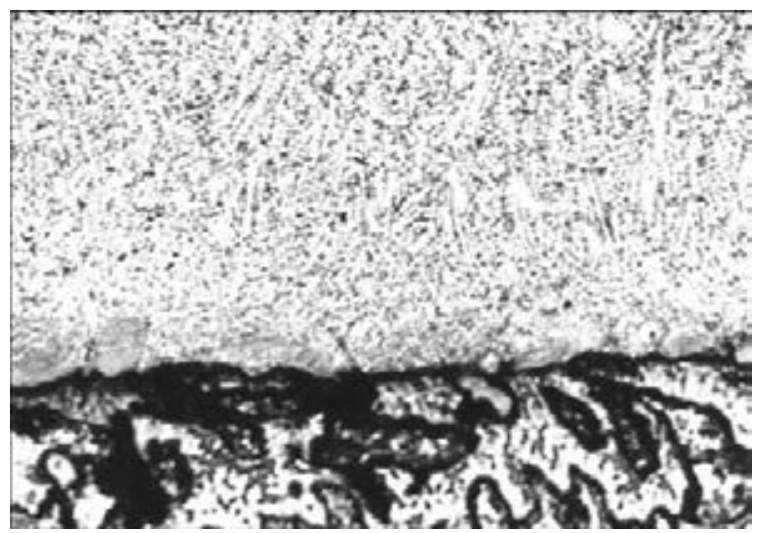

Figure 2. Microstructure $(\times 125)$ of fusion zone of nickel alloy NKh16SR2 with bronze
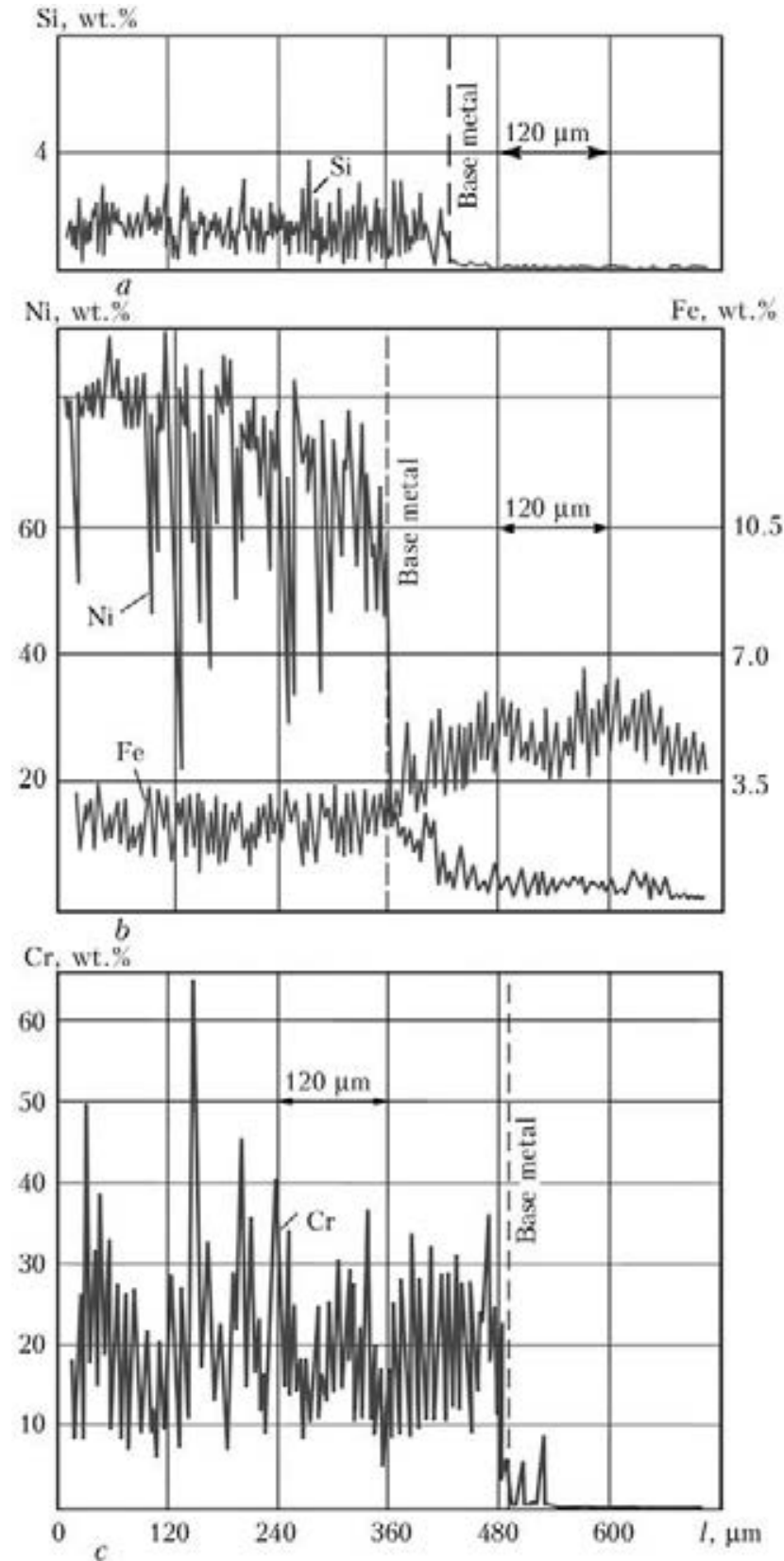

Figure 3. Distribution of alloying elements in the fusion zone of alloy NKh16SR2 with bronze Br.AZhNMts9-4-4-1: $a-$ silicon; $b-$ iron and nickel; $c-$ chromium strength. The fracture of the specimens, deposited by cobalt alloy KKh30N6VSR, during rupture tensile occurs along the base metal. The specimens, deposited by nickel alloys, are fractured along the deposited metal.

Metallographic investigations revealed that in plasma-powder surfacing of nickel and cobalt alloys on aluminum bronze the cracks are absent. The optimal surfacing modes provide reliable $\mathrm{fu}^{-}$ sion of surfacing metal with bronze (Figure 2). In the base and deposited metal near the fusion zone neither depletion nor enrichment by alloying elements are observed. The typical distribution of some elements in the fusion zone of cobalt and nickel alloys with aluminum bronze are illustrated in Figures 3 and 4.

The structure of base metal along the fusion boundary is almost unchanged and typical for aluminum bronze [2]. It consists of dendrites of solid solution, eutectoid and iron component. In surfacing of cobalt and nickel alloys on bronze their structure is somewhat finer than in surfacing on steel. It is evidently affected by a high thermal conductivity of base metal which causes a more rapid cooling of the deposited layer.

Despite the difference in thermal and mechanical properties of base and filler materials, plasmapowder surfacing provides a well-formed deposited layer at a minimum fusion of base metal.

It is known [1] that penetration depth of base metal decreases with increase in arc current and increase in deposition rate, feed rate and fraction of the filler powder. In addition, the shape and dimensions of the deposited product, temperature of its preheating have also a significant influence. During surfacing with oscillations of plasmatron, nonuniformity of penetration depth across the bead width is usually observed, which is connected with different speed of arc movement along the oscillation trajectory. Obtaining uni-

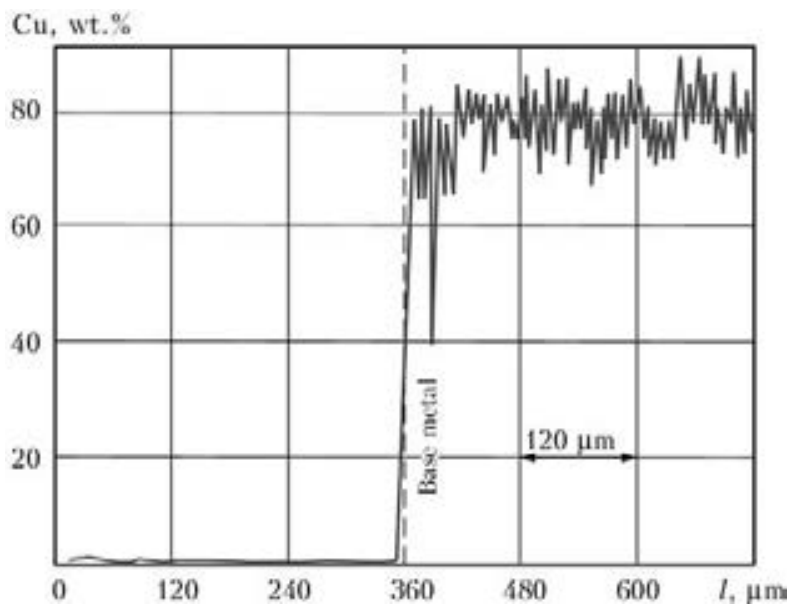

Figure 4. Distribution of copper in the fusion zone of alloy KKh30N6VSR with bronze Br.AZhNMts9-4-4-1 


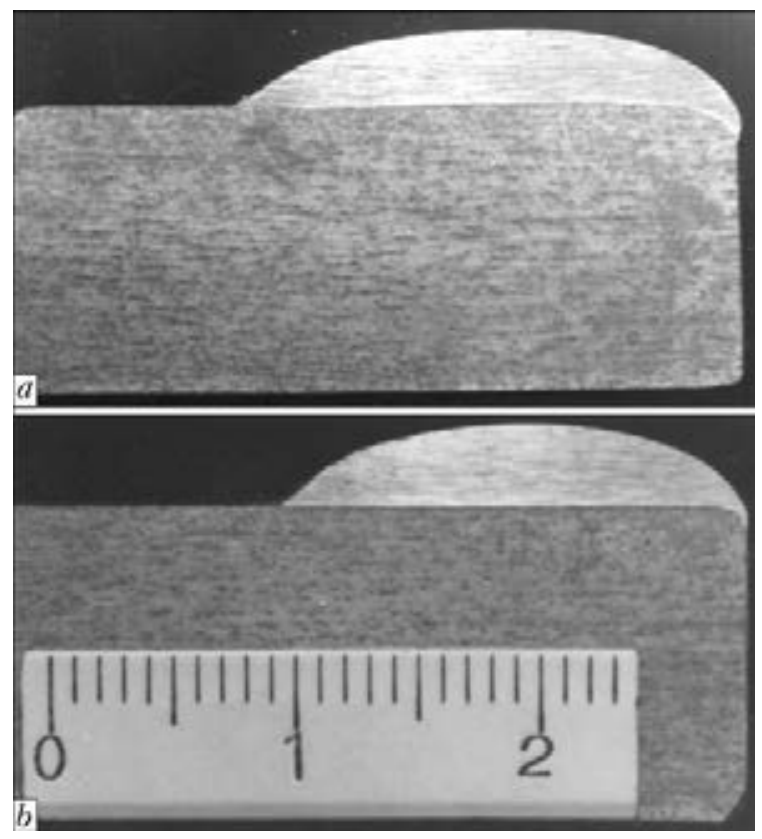

Figure 5. Macrosections of deposited bead: $a-$ without current adjustment; $b$ - with current adjustment across the width of deposited layer

form penetration of base metal is possible by regulating arc current along the trajectory of oscillation (Figure 5). Achieving such technical characteristics of the process is only possible by using computerized equipment. Such equipment provides change in the effective values of arc current and voltage, travel speed of plasmatron, frequency of its oscillations, feed rate of powder and on-line control of these parameters. Change of parameters along the length of deposited bead is preset by a time cyclogram.

Until the recent time at the enterprises for plasma-powder surfacing, universal installations OB 2184 and specialized ones UP-142 were used [3]. The specialized installations were equipped with control system which provides automatic surfacing cycle.

Basing on the experience of operation of such equipment a new control system was developed at the E.O. Paton Electric Welding Institute, providing a full automation of surfacing process and thus optimizing surfacing current and powder feed rate [4]. Using this system the technological algorithms of surfacing were practiced and the discs of bronze Br.AZhNMts9-4-4-1 were deposited (Figure 6). The appearance and macrosection of parts with deposited layer indi-
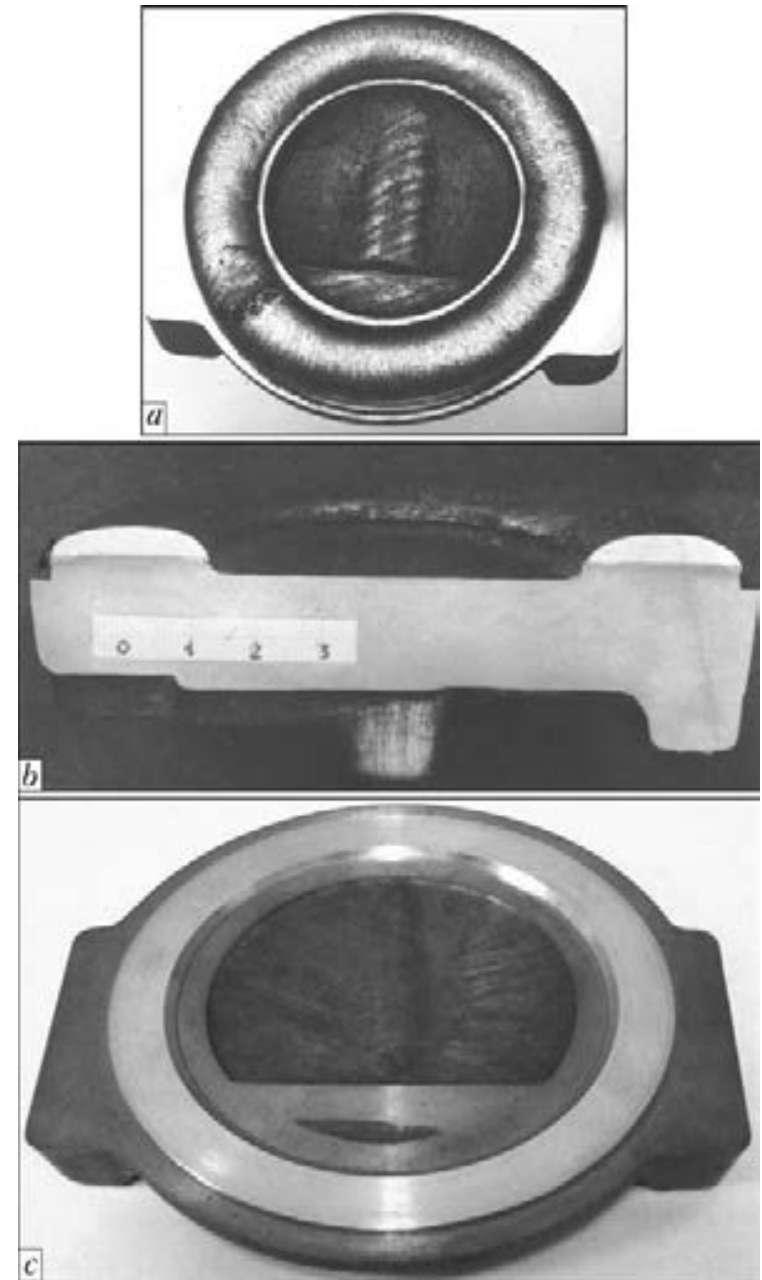

Figure 6. Disc of bronze Br.AZhNMts9-4-4-1 after plasmapowder surfacing using alloy KKh30N6VSR $(a)$, macrosection of this disc $(b)$, and disc after machining $(c)$

cate a good formation of beads. It allows reducing the labor efficiency of machining due to reduction of allowances and obtaining economy of the expensive filler material.

1. Gladky, P.V., Pereplyotchikov, E.F., Ryabtsev, I.A. (2007) Plasma surfacing. Kiev: Ekotekhnologiya.

2. Maltsev, M.V. (1970) Metallography of commercial non-ferrous metals and alloys. Moscow: Metallurgiva.

3. Pereplyotchikov, E.F. (2000) Plasma surfacing. Svarshchik, 2, 8-11.

4. Pereplyotchikov, E.F., Ryabtsev, I.A., Lankin, Yu.N. et al. (2014) Modernization of control system of A1756 machine for plasma-powder surfacing. The $\mathrm{Pa}$ ton Welding J., 12, 41-44. 